\title{
Adhesion of car tires to the road surface during reconstruction of road accidents
}

\author{
Stanislav Evtukov ${ }^{1}$ and Egor Golov ${ }^{1, *}$ \\ ${ }^{1}$ Saint Petersburg State University of Architecture and Civil Engineering, 4, 2- Krasnoarmeiskaya str., \\ 190005, Saint Petersburg, Russia
}

\begin{abstract}
Road and weather conditions have a significant impact on the occurrence of road accidents and their development as events. According to these circumstances, the system "Driver - Car - Road - Environment" identifies certain types of expertise that are engaged in determining the presence and magnitude of the parameters of the road environment that affect the development of the road transport situation. When conducting relevant investigations, the experts calculate the speed and length of the stopping distance of the vehicle, using coefficients that determine the impact of road conditions on the road traffic situation under study. One of these important indicators is the coefficient of adhesion of car tires to the road surface. Due to the lack of technical capability to experimentally determine the coefficient of adhesion at the place of an accident, many experts are forced to use values from the reference literature. This study is devoted to checking the agreement of reference values of this indicator with actual values that correspond to the conditions of driving on Russian roads. To solve this problem, full-scale measurements were made of the coefficient of adhesion of tires with a coating on more than $2000 \mathrm{~km}$ of roads in different regions of Russia (with different climatic and topographic conditions) and the results of field research were analyzed.
\end{abstract}

\section{Introduction}

Road accidents involving overturning vehicles have more serious consequences than other types of road accidents. Overturning the car can be caused by various reasons, in particular, related to road conditions, for example:

- driving a vehicle with skidding on a road surface with a high coefficient of adhesion or with a viscous loose soil into which the wheels crash when they move laterally;

- a sharp turn of the vehicle with a radius that does not correspond to the selected speed under the conditions of stability against overturning on roads with a high value of the coefficient of adhesion (or the coefficient of resistance to the movement of the wheels in the transverse direction on an uneven solid surface). In this case, overturning is possible without skidding.

As can be seen from these points, a large influence on the development of the road transport situation is influenced by the coefficient of (longitudinal) adhesion of tires to the

\footnotetext{
* Corresponding author: egorgoloff@yandex.ru
} 
road surface and its value. The coefficient of adhesion is the ratio of the maximum tangential force acting along the road on the contact area of the interlocked wheel with the road surface to the normal reaction in the contact area of the wheel with the surface $[1,2,3]$.

In the "Driver-Car-Road-Environment" system, two lines of scientific research are allocated for this circumstance:

"Car-Road" - Wear and other destruction of the road surface, changes in the microprofile, rolling coefficients and adhesion;

"Environment (external) - Road" - accounting for influence of the environment on the rolling resistance and adhesion coefficients; changes in the road's micro-profile (the appearance of ice growths).

The coefficient of adhesion of tires to the road surface must be taken into account and determined for the following types of road accidents and road sections: a collision when overtaking on a convex (concave) curve, a collision in the plan (with an exit to the side of the oncoming traffic direction), a collision of oncoming vehicles on a horizontal road section, a vehicle skid caused by the destruction of suspension elements of one of the wheels and/or the destruction of the wheel tire, a collision of vehicles at an unregulated intersection $[4,5]$.

Thus, the definition of the coefficient of friction is especially important during reconstruction of a traffic accident, it may significantly affect the results of calculations of stopping distances, vehicle speed, and to clarify the circumstances causing study emergency. As a result of calculations, the expert is obliged to determine whether the driver violated the requirements of traffic rules, technical means of traffic management (road signs, markings) and whether it was technically possible to prevent a traffic accident $[6,7,8]$.

\section{Materials and Methods}

In the expert practice of investigating the circumstances of road accidents when determining the full stopping distance of the car the formula is used:

$$
S=\left(t_{1}+t_{2}+0.5 t_{3}\right) \frac{V_{c}}{3.6}+\frac{k V_{c}}{254 \varphi}, m
$$

$S$ - length of the full stopping distance of the car, $\mathrm{m}$

$t_{1}-$ driver response time, $\mathrm{s}$

$t_{2}$-brake response time, $\mathrm{s}$

$t_{3}$ - deceleration rise time to the maximum value, $\mathrm{s}$

$V_{c}$-car speed, $\mathrm{km} / \mathrm{h}$

$k$-coefficient of braking efficiency

$\varphi$ - coefficient of adhesion of tires to the road

The coefficient of adhesion of the coating must provide safe driving conditions with the speed permitted by the traffic Rules and be at least 0.3 , and the coefficient of adhesion of the marking must be at least 0.75 of the values of the coefficient of adhesion of the coating.

The coefficient of adhesion is one of the main values that characterize the performance of road surfaces, as well as the interaction of the wheel with the road. Its value is used to judge the safe speed of a car [9.10].

The analysis of numerous data shows that the magnitude of the coefficient of adhesion depends on many different factors, and primarily on the type of coating and its condition, design and material of the tires, the pressure of the air, loads on the wheel, speeds, temperature conditions, values of the sliding and slipping of wheels (table 3.68). 
Often, experts do not have the ability (technically) to experimentally determine the coefficient of adhesion at the site of a road accident, and therefore have to use the reference data presented in table 1 .

Table 1. Coefficient of adhesion for various road surfaces in summer and winter conditions.

\begin{tabular}{|c|c|c|c|}
\hline No & Type of road surface & The condition of the coating & $\begin{array}{l}\text { Coefficient of } \\
\text { adhesion }\end{array}$ \\
\hline \multirow{4}{*}{1} & \multirow{4}{*}{ Asphalt, concrete } & Dry & $0.7-0.8$ \\
\hline & & Wet & $0.5-0.6$ \\
\hline & & Dirty & $0.25-0.45$ \\
\hline & & $\begin{array}{l}\text { Covered with a layer of snow, up to } 5 \\
\mathrm{~cm} \text { thick }\end{array}$ & $0.2-0.4$ \\
\hline \multirow{2}{*}{2} & \multirow{2}{*}{$\begin{array}{l}\text { Cobblestone, paving } \\
\text { stones }\end{array}$} & Dry & $0.6-0.7$ \\
\hline & & Wet & $0.4-0.5$ \\
\hline \multirow{3}{*}{3} & \multirow{3}{*}{ Dirt road } & Dry & $0.5-0.6$ \\
\hline & & Wet & $0.2-0.4$ \\
\hline & & Dirty & $0.15-0.30$ \\
\hline \multirow{2}{*}{4} & \multirow{2}{*}{ Sand } & Wet & $0.4-0.5$ \\
\hline & & Dry & $0.2-0.3$ \\
\hline \multirow{3}{*}{5} & \multirow{3}{*}{ Loam } & Dry & $0.4-0.5$ \\
\hline & & Moistened to a plastic state & $0.2-0.4$ \\
\hline & & Moistened to a fluid state & $0.15-0.25$ \\
\hline 6 & $\begin{array}{ll}\text { Meadow, } & \text { swampy } \\
\text { meadow } & \end{array}$ & Covered with turf & $0.1-0.4$ \\
\hline \multirow{2}{*}{7} & \multirow{2}{*}{ Snow } & Loose & $0.2-0.4$ \\
\hline & & Compacted (rolled road) & $0.3-0.5$ \\
\hline 8 & Ice & Smooth (air temperature below $0^{\circ} \mathrm{C}$ & $0.05-0.1$ \\
\hline
\end{tabular}

The aim of the study was to establish experimentally the correspondence of the reference data of the coupling coefficients with the real ones determined using the PCRS2RDT device (Evenness and adhesion control device). The process of measuring the coefficient of adhesion of tires to the road surface can be represented in the form of an algorithm presented in figure $1[11,12,13]$.

Determination of ambient air and road surface temperature
Ensuring that the speed of the test unit is equal to $(60 \pm 2) \mathrm{km} / \mathrm{h}$ during the entire measurement interval
Water supply to the road surface in front of the measuring wheel;

Measuring the adhesion force from the moment the measuring wheel is locked
Locking the measuring wheel

Fig. 1. Algorithm for measuring the adhesion coefficient. 
The obtained measurement results are subject to mathematical processing - the adhesion force on the measuring section is calculated as the arithmetic mean of the adhesion forces obtained from the measurement results, the adhesion coefficient is calculated using the formula:

$$
\varphi=\frac{F}{N}+K
$$

$F$ - adhesion force on the measuring section, N.

$N$-normal reaction of the road surface in the area of contact with the measuring wheel, $\mathrm{N}$.

$K$ - temperature correction (accepted according to table 2).

Table 2. Value of temperature corrections to the value of the adhesion coefficient.

\begin{tabular}{|c|c|c|c|c|c|c|c|c|}
\hline $\begin{array}{c}\text { Air temperature at the } \\
\text { time of measurement, } \\
{ }^{\circ} \mathrm{C}\end{array}$ & 5 & 10 & 15 & 20 & 25 & 30 & 35 & 40 \\
\hline The correction value & -0.04 & -0.03 & -0.02 & 0.00 & +0.01 & +0.01 & +0.02 & +0.02 \\
\hline
\end{tabular}

In measuring the coefficient of adhesion between tire and the road surface was carried out in 2 regions of Russian Federation: region of the middle Urals (the area, according to the map of road-climatic zoning refers to category II, which includes area of forests with abundant moisture and the soil is in a zone inland climate, characterized by hot summers and cold snowy winters, the average duration of snow cover is 160-175 days, the average annual temperature ranges from $1.0{ }^{\circ} \mathrm{C}$ to $2.5{ }^{\circ} \mathrm{C}$ ) and the North-Western region of the European part of Russia (the climate of the Atlantic-continental is relatively mild winter with frequent thaws and moderately warm, sometimes cool summers, the average temperature in January is $-8 \ldots-11{ }^{\circ} \mathrm{C}$, July $+16 \ldots+18{ }^{\circ} \mathrm{C}$ ). For the study, a complex of measuring mobile airfield and road laboratory KP-514 RDT was used, with a system for measuring the coefficient of adhesion of coatings (a trailer device "PCRS2-RDT" the technical characteristics are presented in table 3, and the general view is shown in figure 2 according to Russian GOST 33078-2014 "Automobile roads of general use. Methods of measuring friction of vehicle wheel with the road surface", as well as manufacturer's instructions AO "SNPC" RDT" [14,15,16].

Table 3. Technical characteristics of the trailer device "PCRS2-RDT".

\begin{tabular}{|l|l|l|}
\hline No & \multicolumn{1}{|c|}{ Parameter } & \multicolumn{1}{c|}{ Value } \\
\hline 1 & The normal load of the wheel on the road. coating, $\mathrm{kN}$ & $3.0 \pm 0.03$ \\
\hline 2 & Range of adhesion coefficient measurements & from 0.1 up to 1.0 \\
\hline 3 & Margin of error, $\%$, not more than & \pm 4 \\
\hline 4 & $\begin{array}{l}\text { Electro-pneumatic control system for locking (braking) the } \\
\text { measuring wheel, the range of adjustment of the duration of } \\
\text { the braking cycle }\end{array}$ & from 2 up to 5 seconds; \\
\hline 5 & The transducer measuring the brake force & Laser \\
\hline
\end{tabular}




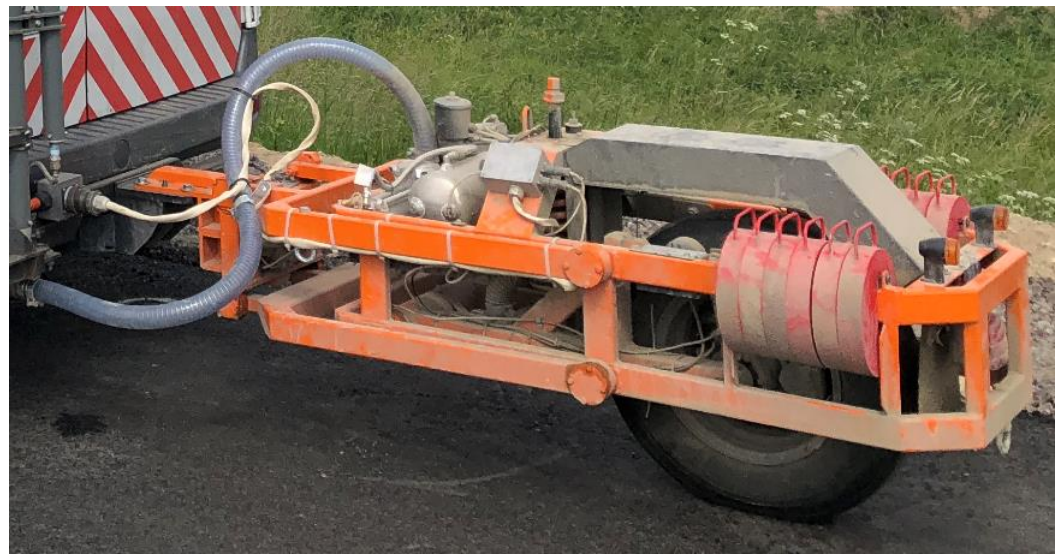

Fig. 2. General view of the trailer device "PCRS2-RDT".

\section{Results}

The adhesion coefficient was measured on more than 50 paved roads with a total length of more than $2000 \mathrm{~km}$, in accordance with all the requirements for this type of measurement. According to the results of the survey of the coefficient of adhesion of each road, a protocol was drawn up, the basis of which was a table (its analogue is presented in table 4).

Table 4. An example of the main indicators reflected in the protocol for measuring the coefficient of adhesion of a car wheel with a road surface.

\begin{tabular}{|c|c|c|c|c|c|}
\hline \multirow{2}{*}{$\begin{array}{l}\text { Measurement } \\
\text { location, } \\
\text { km+m }\end{array}$} & $\begin{array}{c}\text { Value of } \\
\text { the } \\
\text { adhesion }\end{array}$ & \multirow{2}{*}{$\begin{array}{l}\text { The speed of } \\
\text { the vehicle } \\
\text { during } \\
\text { measurement, } \\
\text { km/h }\end{array}$} & \multirow{2}{*}{$\begin{array}{c}\text { Measurement } \\
\text { location, } \\
\mathbf{k m}+\mathbf{m}\end{array}$} & \multirow{2}{*}{$\begin{array}{c}\begin{array}{c}\text { Value of } \\
\text { the } \\
\text { adhesion }\end{array} \\
\begin{array}{c}\text { Forward } \\
\text { stroke } \\
\text { (2 lane) }\end{array} \\
\end{array}$} & \multirow{2}{*}{$\begin{array}{l}\text { The speed of } \\
\text { the vehicle } \\
\text { during } \\
\text { measurement, } \\
\mathrm{km} / \mathrm{h}\end{array}$} \\
\hline & $\begin{array}{c}\text { Forward } \\
\text { stroke } \\
\text { (1 lane) }\end{array}$ & & & & \\
\hline $0+167$ & 0.334 & 60 & $0+152$ & 0.339 & 60 \\
\hline $0+453$ & 0.335 & 60 & $0+521$ & 0.337 & 60 \\
\hline $0+792$ & 0.332 & 60 & $0+872$ & 0.338 & 60 \\
\hline $1+229$ & 0.347 & 60 & $1+267$ & 0.348 & 60 \\
\hline $1+568$ & 0.346 & 60 & $1+601$ & 0.345 & 60 \\
\hline $1+977$ & 0.344 & 60 & $1+843$ & 0.346 & 60 \\
\hline $2+211$ & 0.366 & 60 & $2+346$ & 0.362 & 60 \\
\hline $2+568$ & 0.363 & 59 & $2+598$ & 0.364 & 61 \\
\hline $2+987$ & 0.365 & 59 & $2+973$ & 0.363 & 61 \\
\hline $3+191$ & 0.359 & 59 & $3+199$ & 0.361 & 61 \\
\hline
\end{tabular}

It should be noted that the measurements were made only under favorable weather conditions on a dry surface.

Thus, after analyzing all the measurements made and structuring them, we can present the data in the form of table 4 , where the average values of the adhesion coefficients with a 
division by kilometers are indicated (for reduction, table 4 shows the values of the first 10 $\mathrm{km}$ of long roads).

Table 4. Measured values of adhesion coefficients.

\begin{tabular}{|c|c|c|c|c|c|c|c|c|c|c|c|c|}
\hline \multirow{2}{*}{ No } & \multirow{2}{*}{ Road } & \multicolumn{10}{|c|}{ Kilometer } & \multirow{2}{*}{$\begin{array}{c}\text { Average } \\
\text { value }\end{array}$} \\
\hline & & $0-1$ & $1-2$ & $2-3$ & 3-4 & 4-5 & $5-6$ & 6-7 & $7-8$ & $8-9$ & $9-10$ & \\
\hline 1 & 2 & 3 & 4 & 5 & 6 & 7 & 8 & 9 & 10 & 11 & 12 & 13 \\
\hline \multicolumn{13}{|c|}{ The Region of The Middle Urals } \\
\hline 1 & A & 0.472 & 0.503 & 0.531 & 0.478 & 0.603 & 0.598 & & & & & 0.531 \\
\hline 2 & $\mathrm{~B}$ & 0.336 & 0.346 & 0.364 & 0.360 & & & & & & & 0.352 \\
\hline 3 & $\mathrm{C}$ & 0.312 & 0.292 & 0.374 & & & & & & & & 0.326 \\
\hline 4 & $\mathrm{D}$ & 0.335 & 0.440 & 0.453 & 0.438 & 0.139 & 0.417 & 0.522 & 0.408 & 0.456 & & 0.401 \\
\hline 5 & E & 0.451 & 0.450 & 0.489 & 0.457 & 0.508 & 0.340 & & & & & 0.449 \\
\hline 6 & $\mathrm{~F}$ & 0.516 & 0.501 & 0.479 & & & & & & & & 0.499 \\
\hline 7 & $\mathrm{G}$ & 0.500 & 0.473 & 0.481 & 0.490 & 0.502 & 0.431 & 0.509 & 0.525 & 0.509 & 0.531 & 0.495 \\
\hline 8 & $\mathrm{H}$ & 0.496 & 0.432 & 0.382 & 0.520 & 0.372 & 0.512 & 0.346 & 0.241 & 0.460 & 0.421 & 0.418 \\
\hline 9 & I & 0.422 & 0.366 & 0.444 & 0.472 & 0.499 & 0.472 & 0.479 & 0.411 & 0.450 & 0.431 & 0.445 \\
\hline 10 & $\mathrm{~J}$ & 0.495 & 0.43 & 0.425 & 0.435 & 0.45 & 0.545 & 0.515 & 0.485 & 0.515 & 0.525 & 0.482 \\
\hline 11 & $\mathrm{~K}$ & 0.360 & 0.320 & 0.410 & 0.325 & 0.310 & 0.310 & 0.325 & 0.380 & 0.340 & 0.505 & 0.359 \\
\hline 12 & $\mathrm{~L}$ & 0.480 & 0.485 & 0.480 & 0.465 & & & & & & & 0.478 \\
\hline 13 & $\mathrm{M}$ & 0.425 & 0.415 & 0.490 & 0.510 & 0.520 & 0.475 & 0.475 & 0.495 & 0.490 & 0.530 & 0.483 \\
\hline 14 & $\mathrm{~N}$ & 0.300 & 0.345 & 0.370 & 0.355 & 0.330 & 0.325 & 0.380 & 0.355 & 0.365 & 0.450 & 0.358 \\
\hline 15 & $\mathrm{O}$ & 0.410 & 0.330 & 0.425 & 0.460 & 0.530 & 0.555 & 0.495 & 0.500 & 0.450 & 0.360 & 0.452 \\
\hline 16 & $\mathrm{P}$ & 0.490 & 0.505 & 0.485 & 0.445 & & & & & & & 0.481 \\
\hline 17 & Q & 0.395 & 0.425 & 0.380 & & & & & & & & 0.400 \\
\hline 18 & $\mathrm{R}$ & 0.505 & 0.550 & 0.520 & 0.520 & 0.285 & 0.285 & 0.205 & 0.265 & 0.305 & 0.330 & 0.377 \\
\hline 19 & $\mathrm{~S}$ & 0.393 & 0.483 & 0.459 & 0.476 & 0.491 & 0.543 & 0.450 & 0.497 & 0.429 & 0.374 & 0.460 \\
\hline 20 & $\mathrm{~T}$ & 0.405 & 0.480 & 0.715 & 0.510 & 0.520 & 0.475 & 0.475 & 0.495 & 0.490 & 0.530 & 0.510 \\
\hline 21 & $\mathrm{U}$ & 0.365 & 0.390 & 0.410 & 0.390 & 0.425 & 0.435 & 0.450 & 0.500 & 0.480 & 0.395 & 0.424 \\
\hline 22 & $\mathrm{~V}$ & 0.166 & 0.402 & 0.229 & 0.405 & 0.504 & 0.393 & 0.444 & 0.520 & 0.510 & 0.531 & 0.410 \\
\hline 23 & W & 0.470 & 0.470 & 0.455 & & & & & & & & 0.465 \\
\hline 24 & $\mathrm{X}$ & 0.371 & 0.338 & 0.359 & & & & & & & & 0.356 \\
\hline 25 & $\mathrm{Y}$ & 0.238 & 0.261 & & & & & & & & & 0.250 \\
\hline 26 & Z & 0.245 & 0.260 & 0.255 & 0.380 & 0.338 & 0.407 & 0.408 & 0.404 & & & 0.337 \\
\hline 27 & AA & 0.408 & 0.418 & 0.194 & & & & & & & & 0.340 \\
\hline 28 & $\mathrm{AB}$ & 0.335 & 0.356 & 0.268 & 0.272 & 0.431 & 0.302 & 0.257 & 0.292 & 0.257 & & 0.308 \\
\hline 29 & $\mathrm{AC}$ & 0.480 & 0.390 & 0.310 & 0.190 & 0.310 & 0.365 & 0.295 & 0.300 & 0.480 & 0.245 & 0.337 \\
\hline 30 & $\mathrm{AD}$ & 0.445 & 0.515 & 0.410 & 0.510 & 0.565 & 0.540 & 0.480 & 0.495 & 0.440 & 0.490 & 0.489 \\
\hline 31 & $\mathrm{AE}$ & 0.245 & 0.195 & 0.275 & 0.415 & 0.465 & 0.430 & 0.410 & 0.455 & 0.440 & 0.470 & 0.38 \\
\hline 32 & $\mathrm{AF}$ & 0.435 & 0.451 & 0.446 & 0.592 & 0.536 & 0.419 & 0.409 & 0.398 & 0.419 & 0.440 & 0.455 \\
\hline 33 & AG & 0.245 & 0.242 & 0.184 & 0.215 & 0.259 & 0.482 & 0.217 & 0.316 & 0.400 & 0.304 & 0.286 \\
\hline 34 & $\mathrm{AH}$ & 0.440 & 0.481 & 0.434 & 0.481 & 0.488 & 0.523 & 0.452 & 0.413 & 0.412 & 0.425 & 0.455 \\
\hline 35 & $\mathrm{AI}$ & 0.375 & 0.155 & 0.225 & 0.446 & 0.489 & 0.485 & 0.347 & 0.201 & 0.159 & 0.459 & 0.334 \\
\hline \multicolumn{13}{|c|}{ North-Western region of the European part of Russia } \\
\hline 36 & AJ & 0.280 & 0.405 & 0.535 & & & & & & & & 0.407 \\
\hline 37 & AK & 0.485 & 0.486 & 0.491 & 0.486 & 0.489 & 0.480 & 0.461 & 0.451 & 0.480 & 0.508 & 0.482 \\
\hline 38 & $\mathrm{AL}$ & 0.459 & 0.515 & & & & & & & & & 0.487 \\
\hline 39 & AM & 0.522 & 0.447 & 0.488 & 0.484 & 0.509 & & & & & & 0.49 \\
\hline 40 & AN & 0.540 & 0.568 & 0.488 & 0.542 & & & & & & & 0.535 \\
\hline 41 & $\mathrm{AO}$ & 0.507 & 0.458 & 0.523 & 0.521 & 0.504 & 0.540 & 0.527 & 0.510 & & & 0.511 \\
\hline 42 & AP & 0.439 & 0.494 & 0.434 & 0.422 & 0.431 & 0.432 & 0.436 & 0.457 & & & 0.443 \\
\hline 43 & $\mathrm{AQ}$ & 0.496 & 0.530 & 0.504 & 0.517 & 0.542 & & & & & & 0.518 \\
\hline 44 & AR & 0.48 & 0.557 & & & & & & & & & 0.519 \\
\hline 45 & AS & 0.485 & 0.490 & 0.460 & 0.480 & 0.485 & 0.505 & 0.550 & 0.500 & 0.495 & 0.575 & 0.503 \\
\hline 46 & AT & 0.595 & 0.575 & 0.555 & 0.570 & 0.50 & 0.575 & 0.630 & 0.610 & 0.460 & 0.540 & 0.561 \\
\hline 47 & $\mathrm{AU}$ & 0.420 & 0.410 & 0.470 & 0.515 & 0.585 & 0.545 & 0.500 & 0.520 & 0.575 & 0.600 & 0.514 \\
\hline 48 & $\mathrm{AW}$ & 0.403 & 0.417 & 0.441 & 0.455 & 0.423 & 0.375 & 0.345 & 0.377 & 0.439 & 0.506 & 0.418 \\
\hline 49 & $\mathrm{AX}$ & 0.488 & 0.525 & 0.53 & 0.55 & 0.534 & 0.557 & 0.519 & 0.503 & & & 0.526 \\
\hline 50 & AY & 0.460 & 0.500 & 0.490 & 0.455 & 0.350 & 0.340 & 0.400 & 0.300 & 0.335 & 0.335 & 0.397 \\
\hline 51 & $\mathrm{AZ}$ & 0.490 & 0.570 & 0.490 & 0.460 & 0.490 & 0.460 & 0.490 & 0.510 & 0.500 & 0.560 & 0.502 \\
\hline 52 & BA & 0.335 & 0.335 & 0.375 & 0.405 & 0.426 & 0.355 & 0.385 & 0.29 & 0.375 & 0.385 & 0.367 \\
\hline 53 & BB & 0.451 & 0.472 & 0.486 & 0.484 & 0.490 & 0.437 & 0.463 & 0.425 & 0.452 & 0.432 & 0.459 \\
\hline 54 & $\mathrm{BC}$ & 0.414 & 0.477 & 0.426 & 0.350 & 0.417 & 0.480 & 0.465 & & & & 0.433 \\
\hline 55 & $\mathrm{BD}$ & 0.415 & 0.447 & 0.439 & 0.430 & & & & & & & 0.433 \\
\hline 56 & $\mathrm{BE}$ & 0.397 & 0.401 & 0.409 & 0.413 & 0.425 & 0.444 & & & & & 0.415 \\
\hline \multicolumn{12}{|c|}{ Average value } & 0.434 \\
\hline
\end{tabular}




\section{Discussion}

As shown in table 4, most of the values are in the range 0.2-0.6, that is, the actual coefficient of adhesion is less than the reference value (from table 1), which for dry asphalt is $\varphi=0.7-0.8$. Also, 205 values of the adhesion coefficients (of 422 presented in table 4) are in the range of $0.4-0.5$, which according to table 1 corresponds to a dirty, wet or snowcovered road, which is categorically incorrect - figure 3 shows a photo of weather and climate conditions and the condition of the road surface when measuring the adhesion coefficient.

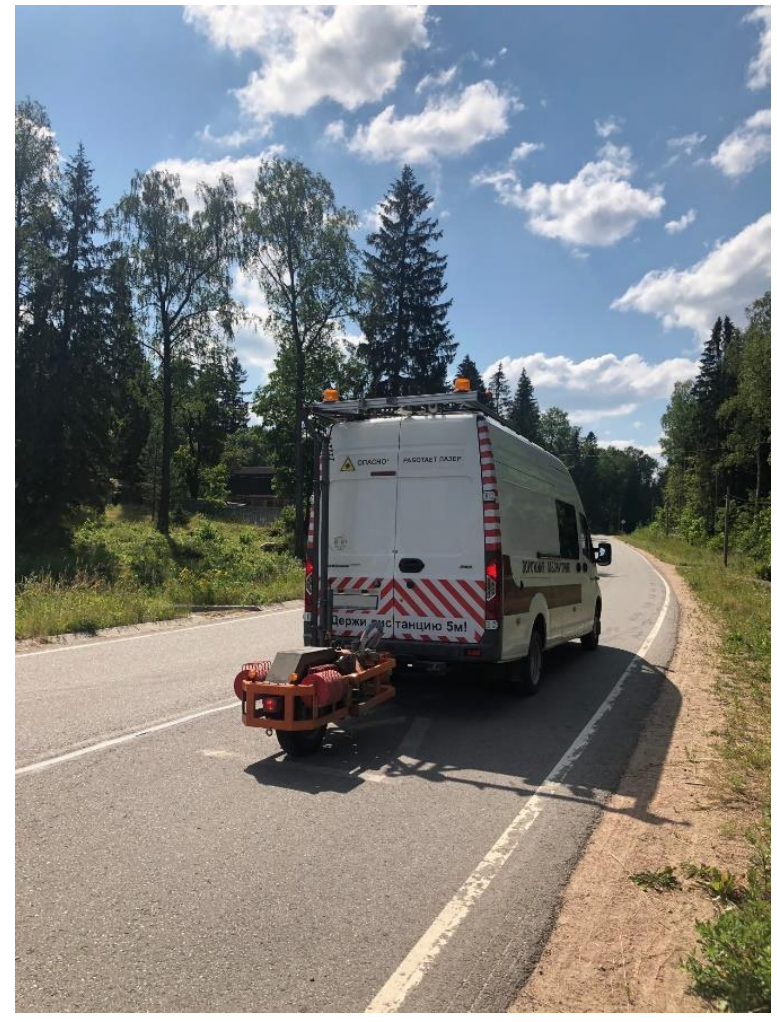

Fig. 4. Weather and climate conditions and the condition of the road surface when measuring the coefficient of adhesion of tires to the road.

The average value of the coefficient of adhesion of tires with a coating for each road surveyed is shown in column 1 , the average value of the presented measurements is 0.434 , and the percentage distribution of the coefficients of adhesion with a step of 0.1 is shown in figure 5 . 


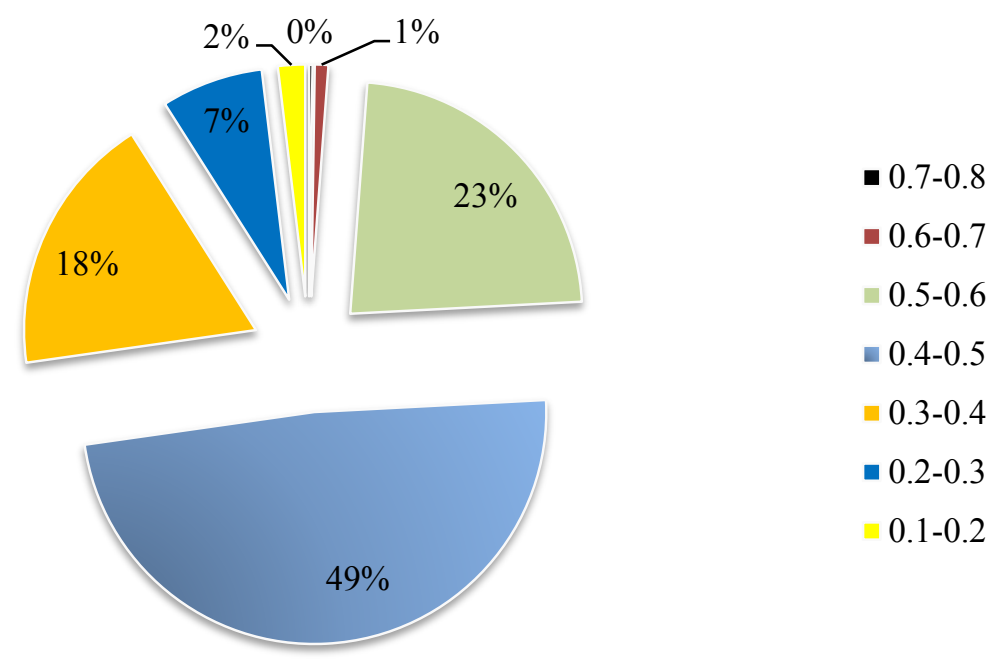

Fig. 5. Percentage ratio of the obtained adhesion coefficients in 0.1 increments.

\section{Conclusions}

Thus, on the example of the surveyed roads, it can be concluded that the reference values of the coefficient of adhesion of tires with a surface (dry) are overstated in comparison with the actual ones. Therefore, when calculating the stopping distance and vehicle speed using reference information, the result may be an error, which categorically affects the expert's conclusion on the case on the road accident. The influence of fluctuations in temperature, humidity and road surface conditions on the coefficient of adhesion of tires to the road is an urgent scientific task and is planned by the authors as further research.

\section{References}

1. X. Li, J. Shao, G. Wei, R. Hou, International Symposium on Pervasive Systems, Algorithms and Networks I-SPAN 2019: Pervasive Systems, Algorithms and Networks, 335-34 (2019) doi:10.1007/978-3-030-30143-9_28

2. K. Doi, T. Sunagawa, H. Inoi, K. Yoh, IATSS Research, Elsevier 39(2), 87-94 (2016) doi: 10.1016/j.iatssr.2016.03.001

3. M.M. Minderhoud, P.H.L. Bovy, Accident Analysis \& Prevention 33(1), 89-97 (2001) doi: 10.1016/S0001-4575(00)00019-1

4. Á. Török, G. Pauer, T. Berta, Procedia Engineering 187, 712-721 (2017) doi: 10.1016/j.proeng.2017.04.445

5. Li-Lu Sun, Dan Liu, Tian Chen, Meng-Ting He, Chinese Journal of Traumatology 22(5), 290-295 (2019) doi: 10.1109/ICTIS.2015.7232140

6. E. Kurakina, S. Evtiukov, J. Rajczykb, Transportation Research Procedia 36, 380-385 (2018) doi: 10.1016/j.trpro.2018.12.111

7. E.V. Kurakina, Bulletin Of Civil Engineers 2(67), 231-237 (2018) doi: 10.23968/19995571-2018-15-2-231-237 
8. S. Evtukov, E. Golov, Transport of the Urals 2(53), 85-89 (2017) doi: 10.20291 / 1815 9400-2017-2-85-89

9. S. Evtiukov, E. Golov, G. Ginzburg, Transportation Research Procedia 36, 157-165 (2018) doi: 10.1016 / j. trpro.2018.12.058

10. S. Evtukov, E. Golov, T. Sazonova, Siberian Transport Forum - Transsiberia (Novosibirsk, 2018)

11. I.S. Gladushevskiy, S.S. Evtyukov, Bulletin Of Civil Engineers 6(71), 175-179 (2018) doi: 10.1051 / matecconf / 201823904018

12. I. Novikov, D. Lazarev, Transportation Research Procedia 20, 463 - 467 (2017) doi: 10.1016 / j. trpro.2017.01.075

13. H. Chena, M. Ishida, A. Namura, K.-S. Baek, T. Nakahara, B. Leban, M. Pau, Proceedings of the 8th International Conference on Contact Mechanics and Wear of Rail, Wheel Systems 271(1-2), 32-3918 (2011) doi: 10.1016/j.wear.2010.10.022

14. F.M. Fernandes, J.C. Pais, Construction and Building Materials 154, 1130-1138 (2017) doi: 10.1016/j.conbuildmat.2017.08.022

15. M.-T. Do, Z. Tang, M. Kane, F. Larrard, Wear 263(1-6), 36-42 (2007) doi: 0.1016 / ј.износ.2006.12.086

16. F. Kilic, J. Hilsmann, IFAC-Papers On Line 49(15), 260-265 (2016) doi: 10.17531 / ein.2017.3.7 